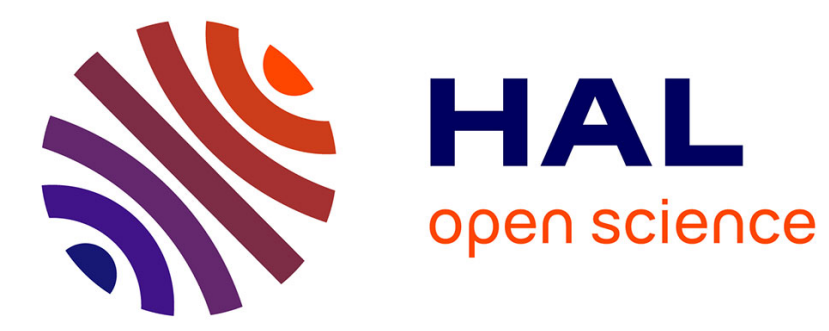

\title{
Publish or Teach? The Role of the Scientific Environment on Academics' Multitasking
}

\author{
Yann Kossi, Jean-Yves Lesueur, Mareva Sabatier
}

\section{To cite this version:}

Yann Kossi, Jean-Yves Lesueur, Mareva Sabatier. Publish or Teach? The Role of the Scientific Environment on Academics' Multitasking. 2013. hal-00825980

\section{HAL Id: hal-00825980 \\ https://hal.science/hal-00825980}

Preprint submitted on 25 May 2013

HAL is a multi-disciplinary open access archive for the deposit and dissemination of scientific research documents, whether they are published or not. The documents may come from teaching and research institutions in France or abroad, or from public or private research centers.
L'archive ouverte pluridisciplinaire HAL, est destinée au dépôt et à la diffusion de documents scientifiques de niveau recherche, publiés ou non, émanant des établissements d'enseignement et de recherche français ou étrangers, des laboratoires publics ou privés. 


\title{
Publish or Teach? \\ The Role of the Scientific Environment on Academics' Multitasking
}

2013, May

\author{
Y. Kossi* \\ J-Y. Lesueur* \\ M. Sabatier** \\ * GATE, Université Lyon 2 \\ ** IREGE, Université de Savoie / LIEPP, Sciences Po Paris
}

\begin{abstract}
The scientific environment might influence university researchers' job designs. In a principal-agent model, researchers must choose between substitutable tasks, publishing or teaching, according to their individual abilities and the scientific and pedagogical context that exists in their universities. This proposed model shows that scientific production can increase, regardless of researchers' abilities, if the scientific environment favours agglomeration effects. The authors test these predictions using an original data set of French economics professors that reveals their individual investments in both teaching and publishing. The econometric results confirm that the tasks conflict and that the scientific context affects researchers' investments in each task.
\end{abstract}

Keywords: scientific production, multitasking, scientific environment

JEL Codes: C3, D2, D8

Contact author: Mareva Sabatier: mareva.sabatier@univ-savoie.fr 


\section{Introduction}

As the pioneering works by Nelson (1959) and Arrow (1962) showed, academic research is essential to the production of knowledge. Knowledge production in turn expands innovation and economic growth (Romer, 1990). Therefore, academic research represents an economic strategy, and many studies seek to understand what determines scientific production. These studies are now a recognized field of research in economics, called the economics of science (Dasgupta and David, 1994; Stephan, 1996; Stephan and Levin, 1997).

A key finding is drawn from this economics of science: individual factors, such as the researcher's age (Diamond, 1986; Stephan and Levin, 1997; Bonaccorsi and Daraio, 2003) or gender (Stephan, 1998), explain only a portion of observed differences in scientific production. Stephan (1996) recommends noting the collective nature of the research and the influences of scientific environment. Empirical evidence notes the influences of a laboratory's or the department's prestige on their researchers' productivity (Cole and Cole, 1973; Long and McGinnis, 1981). For Allison and Long (1990), two complementary mechanisms can explain this result. First, more prestigious departments attract more productive researchers. This selection effect then creates positive and cumulative advantages for the best researchers. This effect has been popularized by Merton (1968) as the Matthew effect. Second, in these departments, research conditions are more favorable, due to spillovers and access to more funding or better equipment. Mairesse and Turner (2002) also show that colleagues' performance increases individual productivity. Using French data from the National Research Council (CNRS), they find that a 10 percent increase the laboratory production induces 0.6 more published papers per researcher (per year). With the same data, Adam and Griliches (1996) find poisitive scale returns, such that department size produces a significant but small effect on individual productivity. Finally, the composition of the department (Carayol and Matt, 2004, 2006), defined by the presence of post-doctoral fellows and the combination of full-time researchers and university professors, also may produce positive externalities.

A large consensus seems thus to emerge to reflect the effects of scientific environment on individual scientific research. However, most of these studies focus on researchers in the United States. Yet other nations, such as France, feature university systems with institutional specificities (cf. U.S. universities) that affect their laboratories and scientific production. For example, academic research traditionally was financed by public funds, allocated mainly according to laboratory size rather than scientific production. Discussions of individual scientific production levels also have been limited mainly to topics related to careers and promotions. In contrast, recent reforms seek to improve universities' autonomy ("LRU» law), create individual incentives for scientific production (research prizes, such as "Prime $\mathrm{d}^{\prime}$ Excellence Scientifique "), and encourage universities to pursue fewer, more transversal projects to achieve agglomeration effects ("Idex " and "Labex " funding projects). These reforms thus create a need to evaluate individual scientific production and its determinants while also arousing concerns among French universities that face more research competition, even as they continue to work to pursue their educational missions. These reforms even could change how professors work-more precisely, how they split their time between research and teaching activities. For example, publication incentives may lead some professors to spend more time in research than in teaching activities. 
But, the economics of science theory ignores this multidimensional nature of professors' activities. Researchers working in a given research context are supposed to have a primary task: scientific production. Yet professors in French universities also must teach at least 192 hours during every academic year. For Fox (1992), teaching and research activities conflict, such that time devoted to one activity decreases the time available for the other. The economics of science seems thus not to deal with the problem of multitasking. This is problematic as multitasking has strong impacts on organizations, jobs' design and incentives. According to personnel economics (Holmstrom and Milgrom, 1991 ; Lazear, 1995), when agents face multiple duties (in a principal-agent framework), incentives can increase their effort and help them efficiently allocate their time among their job activities. But, personnel economics suppose that individual tasks do not depend on collective environment.

Finally, the literature reveals a theoretical gap: the economics of science recommends to consider the influence of the scientific environment on individual research activities but denies multitasking while the personnel economics integrates multitasking but does not take into account collective externalities.

To fullfill this gap, we therefore propose to study a multitasking setting to determine how professors allocate their time between research and teaching duties using a principal-agent model (Prasad, 2009), in which professors are heterogeneous in abilities to research and teach. With this model, we introduce the effect of the scientific context on the time devoted to each task. In turn, we predict that professors must be assigned tasks according to their relative abilities but also that a dynamic scientific context can improve their individual production, whatever their abilities.

We use an original data set to test these predictions. With our novel database, we observe, for a sample of French economics professors, their scientific production and their time investments in pedagogical and administrative duties. We also collect indicators of the institutional context, related to both research and pedagogy. With these data, we estimate a publication score and teaching hours simultaneously, using a three-step least squares methodology. The results clearly confirm our theoretical predictions: Research and teaching tasks are conflicting demands for professors, but a more favorable scientific context can improve their scientific production, whatever the professors' abilities.

We structure the remainder of this article as follows: The next part presents the principalagent model with multitasking and externalities due to the scientific context. After we detail the data we used to test our theoretical predictions, we present the empirical strategy and then discuss our results. Finally, we conclude with some implications and limitations.

\section{Model}

\section{A. General model}

We here address a principal-agent problem in which the risk-neutral principal, the university, assigns two tasks to the risk-averse agents, the professors: teaching or management (T) and research (R). As in MacDonald and Marx (2001), tasks are substitutable to agents but complementary to the principal. Each agent therefore splits available time (normalized to one unit) between the two tasks, such that when $t$ defines the amount of time devoted to research activities, $(1-t)$ refers to the time devoted to teaching and 
managerial tasks. As Prasad (2009) and Thiele (2010) recognize, agents exhibit different skills with regard to conducting the two tasks. These task-specific abilities, $\alpha$ and $\beta$, influence the costs to agents to perform a task. Therefore, the cost function for a single agent $i$ is given by:

$$
c\left(t_{i}\right)=\alpha t_{i}+\beta\left(1-t_{i}\right)
$$

We define three types of agents: a generalist and two specialists. A generalist faces the same costs to perform each task, so $\alpha=\beta$. His or her costs function can be written as $c\left(t_{i}\right)=\alpha$. A teaching specialist instead faces a higher cost of performing research, so $\alpha>\beta$. Finally, for a research specialist, we have $\alpha<\beta$.

In turn, for each task, the outcome is either a success (1) or a failure (0). The probability of success reflects the individual time spent on the activity. We here suppose that individual productions do not depend on environment. We relax this hypothesis in the next part.

If both tasks fail, the principal obtains a minimal level of production $\bar{y}$. If only one task succeeds, the principal obtains an output that depends on the time spent on this task. If the successful task involves research activities, the principal's output is $Q_{R}=\bar{y}+a \sqrt{t_{i}}$. If instead teaching activities succeed, the output is $Q_{T}=\bar{y}+b \sqrt{\left(1-t_{i}\right)}$. In these latter cases, $a$ and $b$ are technological efficiency parameters that depend on the scientific, pedagogical, and administrative context. Finally, the principal obtains the maximal output when both tasks succeed, such that $Q_{T R}=\bar{y}+a \sqrt{t_{i}}+b \sqrt{\left(1-t_{i}\right)}$. Thus, if specialized agents succeed, the principal obtains a lower output than if both tasks were successfully completed by generalists. Tasks are complementary to the principal.

The principal defines agents' compensation by the vector $c \equiv\left[w, w+p_{T}, w+p_{R}, w+p_{T}+\right.$ $p R$, such that agents get paid $w$ if the two activities fail, $w+p T$ if only teaching and managerial tasks succeeds, $w+p_{R}$ if only research activities succeed, and $w+p_{T}+p_{R}$ if both activities succeed.

Table 1 presents these outcomes, their associated probabilities, the principal's outcomes (production), and the resulting contracts.

Table 1: The principal-agent problem: a synthesis

\begin{tabular}{|l|c|c|c|c|}
\hline Outcomes & $(1,1)$ & $(1,0)$ & $(0,1)$ & $(0,0)$ \\
\hline Probabilities & $t(1-t)$ & $t^{2}$ & $(1-t)^{2}$ & $t(1-t)$ \\
\hline Production & $\bar{y}+a \sqrt{t}+b \sqrt{1-t}$ & $\bar{y}+a \sqrt{t}$ & $\bar{y}+b \sqrt{1-t}$ & $\bar{y}$ \\
\hline Contracts & $w+p_{T}+p_{R}$ & $w+p_{R}$ & $w+p_{T}$ & $w$ \\
\hline
\end{tabular}

Furthermore, agents are risk averse and seek to maximize their expected utility. Let $u$ be the agent's utility function; it is strictly concave and twice continuously differentiable. For a given contract and time allocation, utility can be defined as:

$$
\begin{aligned}
& u_{i}=t_{i}\left(1-t_{i}\right) u\left(w+p_{R}+p_{T}\right)+t_{i}^{2} u\left(w+p_{R}\right) \\
& +\left(1-t_{i}\right)^{2} u\left(w+p_{T}\right)+t_{i}\left(1-t_{i}\right) u(w)-C_{i}\left(t_{i}\right)
\end{aligned}
$$


The principal's expected profit is:

$$
\pi\left(t_{i}\right)=\sum_{i}\left\{4 \bar{y}+2 a \sqrt{t_{i}}+2 b \sqrt{1-t_{i}}-W_{i}\right\}
$$

with $W_{i}$ is the expected cost associated with the contract and time allocation.

When agents have no private information (about abilities or time allocation), the principalagent problem is:

$$
\operatorname{Max} \pi\left(w, p_{R}, p_{T}, t_{i}\right)
$$

subject to an individual rationality constraint:

$$
u_{i}\left(w, p_{R}, p_{T}, t_{i}\right) \geq u_{0}
$$

With Proposition 1 we examine how the time devoted to research depends on the relative abilities of agents; the proofs are in the Appendix.

Proposition 1: In a full-information framework, it is optimal for an agent to allocate more time to his or her low-cost activity.

The optimal time devoted to research thus given by :

$$
t^{*} \text { such as: } \frac{\partial \pi}{\partial t_{i}}=0 \leftrightarrow \frac{a}{\sqrt{t_{i}}}-\frac{b}{\sqrt{1-t_{i}}}=(\alpha-\beta) \times h^{\prime}\left(\alpha t_{i}+\beta\left(1-t_{i}\right)+u_{0}\right)
$$

with $h()=.u^{-1}($.$) and h^{\prime}()>$.0 (see the Appendix).

Next, consider what happens for each type of agent.

Let us discuss what happen for each type of agent.

a) Generalist ( $\alpha=\beta$ )

For a generalist, which is the condition we use as a benchmark in the rest of this article, the optimal time for research is: $t_{G}^{*}=\frac{a^{2}}{a^{2}+b^{2}}<1$

\section{b) Specialist in research $(\alpha<\beta)$}

For a specialist in research tasks, the optimal time for research is:

with an upward limit at one.

$$
t_{R}^{*}>t_{G}^{*}=\frac{a^{2}}{a^{2}+b^{2}}
$$

c) Specialist in teaching $(\alpha>\beta)$

For a specialist in teaching and managerial activities, the optimal time for research is:

with a slowdown limit at zero.

$$
t_{T}^{*}<t_{G}^{*}=\frac{a^{2}}{a^{2}+b^{2}}
$$


With these equations, we can compare the optimal research times for the three profiles, which reveals $t_{T}^{*}<t_{G}^{*}<t_{R}^{*}$. A specialist devotes more time to the task that he is good for, compared to a generalist. A specialist devotes more time to the task that she or he is good at, compared with a generalist. This result is more intuitive if we assume $a$ and $b$ are equal to 1. In this case, as in Prasad (2009) and MacDonald and Marx (2001), a generalist splits her or his time equally across the two tasks, whereas a specialist rationally chooses to favor the less costly activity. Proposition 1 is in line with Fox's (1992) findings, using data on U.S. researchers in four social sciences (economics, political science, psychology, and sociology), that more productive researchers spend less time teaching and more time in research activities.

Finally, for the principal (university), it is optimal to assign professors to tasks according to their relative abilities: Those with better research skills should specialize in research, whereas those with poorer research abilities should combine research with managerial and teaching activities. This finding contradicts hierarchical theory (Sattinger, 1975; Rosen, 1982; Waldman, 1984) and proposes the most efficient workers should be assigned to managerial duties.

These equilibrium properties derive from a general framework, in which the principal and agents have symmetric information. However, the principal might observe only the agents' type, not their time allocations. In this asymmetric case, the principal must solve a moral hazard problem:

$$
\operatorname{Max} \pi\left(w, p_{R}, p_{T}, t_{i}\right)
$$

subject to the individual rationality constraint:

$$
u_{i}\left(w, p_{R}, p_{T}, t_{i}\right) \geq u_{0}
$$

as well as to the moral hazard constraint given by:

$$
t^{*} \in \arg \max u_{i}\left(w, p_{R}, p_{T}, t_{i}\right)
$$

At the equilibrium, payments $x_{i}$ are equal for all outcomes, so the individual rationality constraint depends on $t$ only, through the cost function. We thus have:

$$
u\left(x_{i}\right)=u_{0}+\alpha t_{i}^{*}+\beta\left(1-t_{i}^{*}\right)
$$

In the case of a generalist $(\alpha=\beta)$, expected utility does not depend on $t$, so $t_{G}^{*}=\frac{a^{2}}{a^{2}+b^{2}}$.

However, if agent $i$ is a specialist, her or his expected utility is maximized when she or he devotes all her or his time to the personally less costly task. So if $\alpha<\beta$, we obtain $t_{R}=1$ (research specialist) and if $\alpha>\beta$, we have $t_{T}=1$ (teaching and managerial activities specialist). These two solutions can be treated as the limiting cases for our general full information framework (Prasad, 2009).

However, even in the asymmetric case, this general framework still assumes that agents' production is perfectly independent of the scientific environment. This individual-level approach to predicting scientific production thus neglects the collective nature of research (Stephan, 1996). In the next section, we introduce the role of the scientific environment. 


\section{B. Multitasking and the scientific environment}

In a multitasking context, spillovers due to the scientific environment could influence how professors split their available time. Following Griliches (1979), we anticipate that scientific production results from access to knowledge stocks, $K$. Therefore, let $y_{R}=a(K) \sqrt{t}$ be individual research production. The stock of knowledge depends on the number of researchers in the department and the time they devote to research tasks, such that $K=$ $N t$. Now suppose that $a(K)=a \sqrt{K}=a \sqrt{N t}$. In that case, we can write: $y_{R}=a t \sqrt{N}$

Furthermore, in a full information context, the principal-agent problem becomes:

$$
\operatorname{Max} \pi\left(w, p_{R}, p_{T}, t_{i}\right)=2 a t_{i} \sqrt{N}+2 b \sqrt{1-t}+4 \bar{y}-W_{i}
$$

subject to an individual rationality constraint:

$$
u_{i}\left(w, p_{R}, p_{T}, t_{i}\right) \geq u_{0}
$$

With Proposition 2 we examine how the scientific environment affects the time devoted to research, with the proofs again provided in the Appendix.

Proposition 2: In a full-information framework, it is optimal for an agent to allocate more time to research when scientific externalities arise, whatever his or her relative ability, but only if the stock of knowledge in the department is sufficient.

Therefore, the optimal time devoted to research in this case is given by :

$$
t^{* *} \text { such as: } \frac{\partial \pi}{\partial t_{i}}=0 \leftrightarrow 2 a \sqrt{N}-\frac{b}{\sqrt{1-t_{i}}}=(\alpha-\beta) \times h^{\prime}\left(\alpha t_{i}+\beta\left(1-t_{i}\right)+u_{0}\right)
$$

with $h()=.u^{-1}($.$) and h^{\prime}()>$.

Then, we can outline the outcomes for each type of agent.

a) Generalist ( $\alpha=\beta$ )

For a generalist, the optimal time for research is:

$$
t_{G}^{* *}=1-\frac{b^{2}}{4 a^{2} N}<1
$$

If we compare this optimal time with and without externalities, we find that $t_{G}^{* *}>t_{G}^{*}$.

Furthermore, we note that $t_{G}^{* *}=t_{G}^{*}$ if $N=\frac{a^{2}+b^{2}}{4 a^{2}}=N^{*}$. When the number of researchers in the department is greater than $N^{*}$, a generalist can devote more time to research tasks if externalities are present (compared with a context without externalities). Finally, $t_{G}^{* *}$ has the following properties: $\lim _{N \rightarrow \infty} t_{G}^{* *}=1$ and $\lim _{N \rightarrow \frac{b^{2}}{4 a^{2}}} t_{G}^{* *}=0$

Graphically, we thus have: 
Graph 1: Stock of capital and time allocation of generalists

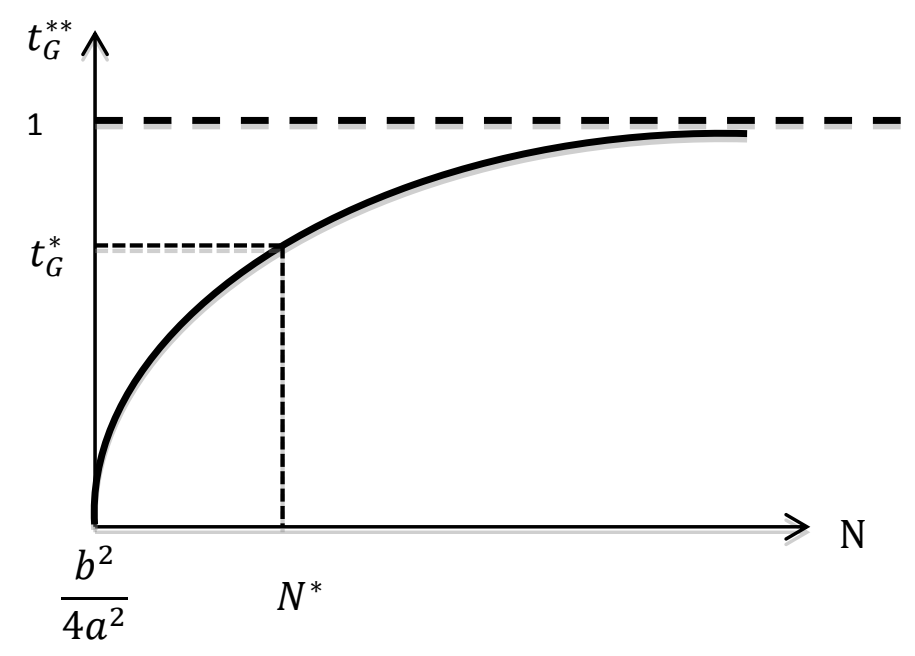

As Graph 1 shows, externalities do not always incite generalists to devote more time to research. It depends on the number of researchers in the department. If $N>N^{*}$, spillovers inside the department lead generalists to specialize more in research. But below $N^{*}$, generalists are not incited to spent more time on research compared with a context without externalities.

\section{b) Specialist in research $(\alpha<\beta)$}

For someone who specializes in research tasks, in the presence of scientific externalities, the optimal time for research is : $t_{R}^{* *}>t_{G}^{* *}=1-\frac{b^{2}}{4 a^{2} N}$

\section{c) Specialist in teaching $(\alpha>\beta)$}

For someone who specializes in teaching and managerial activities, the optimal time for research with externalities is : $t_{E}^{* *}<t_{G}^{* *}=1-\frac{b^{2}}{4 a^{2} N}$

Finally, accounting for scientific externalities in a department does not affect the hierarchy of agents in terms of research time, because $t_{E}^{* *}<t_{G}^{* *}<t_{R}^{* *}$. Externalities do not distort individual abilities to complete each task, but they do alter the time devoted to research for each type of agents, if the number of researchers in the laboratory exceeds a threshold $N^{*}$. The concentration of knowledge increases the time devoted to research activities, even if professors with greater teaching abilities spend less time on research than does a generalist or a research specialist, which suggests the existence of agglomeration effects for academics (Aghion, 2010). Our principal-agent model leads thus to two main conclusions:

- $\quad$ Tasks must be assigned according to relative individual abilities.

- The time devoted to research can be increased for all professors, whatever their abilities, when the laboratory size is sufficient, due to agglomeration externalities. 


\section{Data}

Following our theoretical framework, we next test how professors allocate their available time in a multitasking context and whether this allocation changes with the scientific context. This empirical analysis clearly departs from extant literature, in that we do not focus solely on scientific production but also are interested in the pedagogical dimension, which often remains unobserved.

Therefore, we built an original data set using administrative data from the French Ministry of Education. With these data, we can observe 240 full professors in economics department, each of whom participated in the first three national competitions (2009-2011) for the "Prime d'Excellence Scientifique" (PES). Introduced in 2009, the PES competition involves a search for the most productive professors in each discipline in the four years prior to the competition. Similar to a tournament, candidates get ranked on the basis of four criteria: scientific production, quality of PhD supervising, scientific responsibilities, and scientific reputation at national and international levels. To enter this competition, applicants provide their scientific production, their number of teaching hours per year, and their administrative duties, together with a curriculum vita that indicates their individual characteristics, including age, experience, gender and their institutional affiliation.

Before describing the tasks and individual attributes, we outline our sample. The 240 full professors in economics represent $44 \%$ of the total population, and their demographic characteristics are very similar to those of the overall population (see Table 2).

Table 2: Sample and population of French economics professors

\begin{tabular}{|l|c|c|}
\hline & Population & PES Sample \\
\hline Number & 547 & 240 \\
\hline \% of male & $81,2 \%$ & $77,9 \%$ \\
Age (in average) & 51,7 & 49,2 \\
\hline \multicolumn{2}{|c|}{ Source: Ministry of Education, 2011} \\
\hline
\end{tabular}

However, the scientific and pedagogical activities of the full population are unobservable, so we cannot determine if full professors in our sample are totally representative of all full professors in economics. We suspect that participation in the PES competition is not random but instead depends on observed and unobserved attributes. Unfortunately we cannot address this selection problem; to correct it, we could need instrumental variables that could explain just participation in the competition, not our two key variables. The administrative data we use, though extensive and unique, are not rich enough to reveal such variables. Thus, our results must be discussed with caution, due to the risk of selection bias. 
Table 3: Variables and descriptive statistics

\begin{tabular}{|c|c|c|c|c|c|}
\hline Variable & Description & Mean & Std. Dev. & Min & Max \\
\hline ips & Publication score & 6.303 & 6.130 & 0 & 40.593 \\
\hline hens & Teaching hours + administrative duties & 210.342 & 61.931 & 54 & 512 \\
\hline male & $=1$ if male & 0.779 & & 0 & 1 \\
\hline $\exp$ & Years of experience & 18.292 & 9.198 & 2 & 40 \\
\hline $\operatorname{exp2}$ & Square of experience & 418.833 & 388.789 & 4 & 1600 \\
\hline hi0506 & $\mathrm{h}$-index during the previous period & 6.525 & 5.976 & 0 & 44 \\
\hline Icitun & $\begin{array}{l}\text { Citation index of researchers of the same } \\
\text { university (logs) }\end{array}$ & 2.439 & 0.843 & 0 & 4.617 \\
\hline Icitun2 & Icitun squared & 6.659 & 4.257 & 0 & 21.319 \\
\hline scorup & $\begin{array}{l}=1 \text { if the citation score of the university is } \\
\text { increasing }\end{array}$ & 0.321 & & 0 & 1 \\
\hline ratio & Number of students/Number of teachers & 19.860 & 2.139 & 14.709 & 27.425 \\
\hline \multicolumn{6}{|c|}{ Fields of research } \\
\hline jelBN & $\begin{array}{l}\text { History of Economic Thought and Economic } \\
\text { History }\end{array}$ & 0.050 & & 0 & 1 \\
\hline jelC & Mathematical and Quantitative Methods & 0.088 & & 0 & 1 \\
\hline JelD & Microeconomics & 0.092 & & 0 & 1 \\
\hline jelE & Macroeconomics and Monetary Economics & 0.167 & & 0 & 1 \\
\hline jelF & International Economics & 0.050 & & 0 & 1 \\
\hline jelG & Financial Economics & 0.071 & & 0 & 1 \\
\hline jelHK & Public Economics and Law and Economics & 0.067 & & 0 & 1 \\
\hline jellJ & $\begin{array}{l}\text { Health, Education, and Welfare and Labor } \\
\text { economics }\end{array}$ & 0.088 & & 0 & 1 \\
\hline jelL & Industrial Organization & 0.117 & & 0 & 1 \\
\hline JelM & $\begin{array}{l}\text { Business Administration and Business } \\
\text { Economics; Marketing; Accounting }\end{array}$ & 0.050 & & 0 & 1 \\
\hline jelO & $\begin{array}{l}\text { Economic Development, Technological Change, } \\
\text { and Growth }\end{array}$ & 0.050 & & 0 & 1 \\
\hline jelQ & $\begin{array}{l}\text { Agricultural and Natural Resource Economics; } \\
\text { Environmental and Ecological Economics }\end{array}$ & 0.067 & & 0 & 1 \\
\hline jelR & $\begin{array}{l}\text { Regional, Real Estate, and Transportation } \\
\text { Economics }\end{array}$ & 0.046 & & 0 & 1 \\
\hline
\end{tabular}

To measure individual scientific production, we used two indicators. A scientific production index, ips, is calculated as the number of articles published during the four years prior to the competition, weighted by the quality of the journal and number of co-authors. This indicator has been chosen as it is used as an indicator in promotion decisions in French universities (Levy-Garboua, 2008). We also used other indicators of scientific production, such as the $h$ index restricted to four years before the competition. Our results are not sensitive to the choice of indicators.

To calculate the ips score, we counted all articles published in journals included in the economics journal categorization of the French National Scientific Research Committee (CNRS). We use this ranking (which only pertains to France) to account for the quality of publications. We adopt a decreasing five-point score $(5=$ an article published in the most 
prestigious journals, $1=$ a publication in the less prestigious journals). For each publication, we also control for co-authorship, dividing each article's score by the square root of the number of co-authors, to capture the individual PES applicant's contribution to each copublished article. Thus, an individual scientific production index is given by:

$$
\operatorname{ips}_{\mathrm{i}}=\sum_{\mathrm{j}}^{\mathrm{n}_{\mathrm{i}}}\left(\frac{\text { scor }_{\mathrm{j}}}{\sqrt{\text { ncoaut }_{\mathrm{j}}}}\right)
$$

where $\mathrm{n}_{\mathrm{i}}$ is the number of articles published by a given professor $i$, score $\mathrm{s}_{\mathrm{i}}$ the score of a given journal, $j$, and ncoaut $_{j}$ refers to the number of co-authors for each published paper, $j$.

The descriptive statistics reveal the large dispersion of IPS scores, from 0 to 40.59 with a mean of 6.303. We also observe that the distribution of our scientific production index is asymmetric: A very high proportion of professors have low scores and few researchers have very high scores (see Graph 2), in accordance with Lotka (1926)'s law.

Graph 2: Distribution of the scientific production index

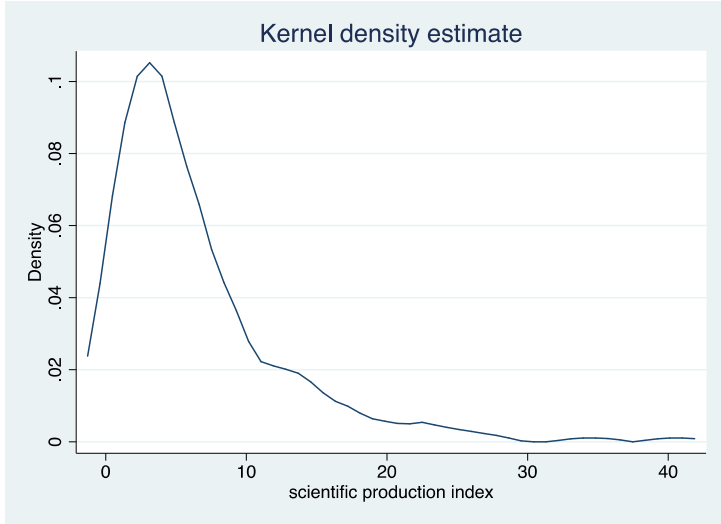

Prior literature also has noted a Matthew's effect (Merton, 1968), which refers to path dependency in scientific production scores. Therefore, we construct another scientific production index to take past production into account, using a lagged $h$ index (Hirsch, 2005) to measure scientific output, weighted by the number of citations per publication between 1985 and the year preceding the competition. We again find a strong asymmetric distribution of researchers' past $h$ indexes, with a mean value of 6.52 and a large dispersion between 0 and 44. Finally, past scientific production could reflect unobservable research abilities, which is a key parameter of our principal-agent model.

The main originality of our dataset is to also identify pedagogical and administrative activities. For each professor, we measure the mean of annual teaching hours at the undergraduated or graduated level (bachelor degree, master degree and PhD degree) in the last two academic years before the PES competition. Note that, in the French academic system, professors are civil servant and must teach at least 192 hours per academic year. Of course, they can choose to teach more. They then receive an additional salary, commensurate with the number of overtime hours performed.

In addition to teaching duties, professors can be involved in administrative tasks. These administrative activities can be done at the department level (as dean of the department or of the scientific laboratory), at the university level (as being member of the University council, such as President of the University) or at a national level (as being member of 
French National Council of Universities or of the National Scientific Research Committee, etc.). For all these duties, professors receive a premium, calculated as a given number of equivalent teaching hours (according to a national referential) ${ }^{i}$. To take into account the wide diversity in the educational and administrative investment, we decided to aggregate teaching hours and hours in administrative duties. The obtained index, denoted hens, varies between 54 and 512 hours per year with a mean value at 210 (see graph 3), a level very closed to the teaching statutory service. Note that, in our sample, $37 \%$ of the professors teach less than the conventional service (less than 192 hours). This could be explained by sabbatical vacancies, allowing professors to concentrate on their research project and to be exempted of any teaching duties for one semester or a complete year.

Graph 3: Distribution of the teaching and administrative hours

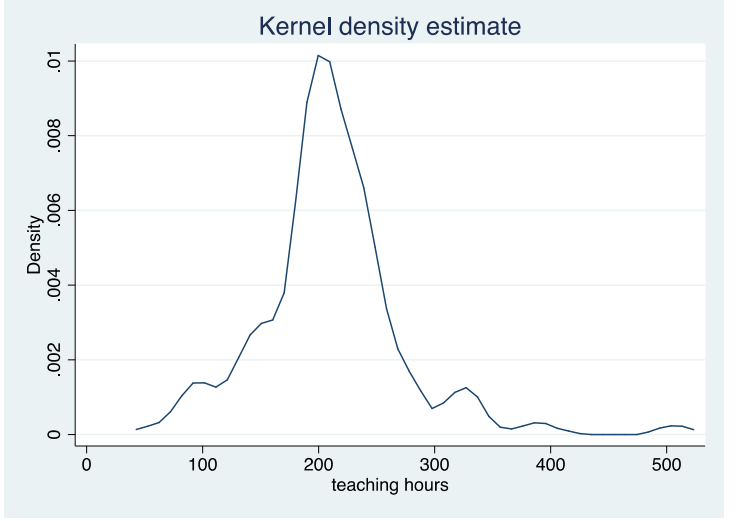

The descriptive statistics thus show great heterogeneity in professors' investments in research and teaching. Some professors specialize in teaching or research; others are generalists. These types may reflect their individual abilities, which we denoted $\alpha$ and $\beta$ in our theoretical framework. However, their abilities are often unobservable. Therefore, we propose to identify each professor's type, according to his or her level of investment in each task, compared against the median investment observed in the sample. Thus,

- $\quad$ Generalists are those professors who achieve higher publication and teaching scores than the median.

- $\quad$ Research specialists are professors who score higher only on the publication side.

- Teaching specialists are those who score higher only on the teaching side,

- $\quad$ Professors who score lower than the median on both tasks are free riders.

In addition to their scientific production and investment in teaching and administrative duties, our data reveal some individual attributes about the professors, as well as their fields of research, according to a set of dummies reflecting the JEL classifications of their publications. Following Rauber and Ursprung (2008), we anticipate that research fields might have two effects on scientific production. First, some fields could be more prolific because of their high concentration of scientists, large international networks, or complementarities with other fields (e.g., econometrics, game theory). Second, some research fields might have been enhanced by consulting activities in the private sector. Professors rationally might choose to devote more time to these lucrative activities than to academic publications. We also consider research fields as determinants of teaching hours. Interactions between research and teaching activities might induce some scope economies or, conversely, reduce teaching competencies. We thus wonder if it might be difficult to assign enough courses to 
ultra-specialist teachers in their fields of expertise. In contrast, professors with a broad research field (e.g., macroeconomics, microeconomics, public economics, quantitative techniques) could be asked more readily to teach the wide range of courses needed.

Finally, we seek to identify whether the scientific environment influences the time devoted to research and teaching tasks. The PES data set does not directly reveal this information but instead indicates the institutional affiliation of each professor. With this information, we can collect additional data to identify the professors' work environment. First, to identify the scientific context, we use impact factors for French economic departments, as provided by Bosquet and Combes (2011). Departmental impact factors, denoted citun, refer to the sum of individual impact factors (production weighted by citations, based on Google Scholar) of all members during 2004-2008, or immediately before the PES competition. In addition to this static indicator, we use a dynamic measure of the departments in which the impact factor has increased most strongly (scoreup). Such a favorable evolution in the scientific context occurs among $35.5 \%$ of the departments observed in our sample.

In this empirical work, we can also identify some characteristics of the teaching and administrative context which can influence the individual investment in teaching activites. We mobilized data from the French Ministry of Education about the number of students and number of professors per university (in 2010). We constructed a ratio of these two variables (variable "ratio" in Table 3) that gives the number of students per professor.

Graph 4 presents the distribution of individual scientific production scores and pedagogical duties according to the collective environment. For the scientific context, we define two departmental categories: high impact factors (25\% highest scores) and low impact factors (25\% lowest scores). For pedagogical context, we adopt the same method, according to the value of the ratio of students to professor.

Graph 4: Distribution of tasks scores according to scientific and pedagogical contexts
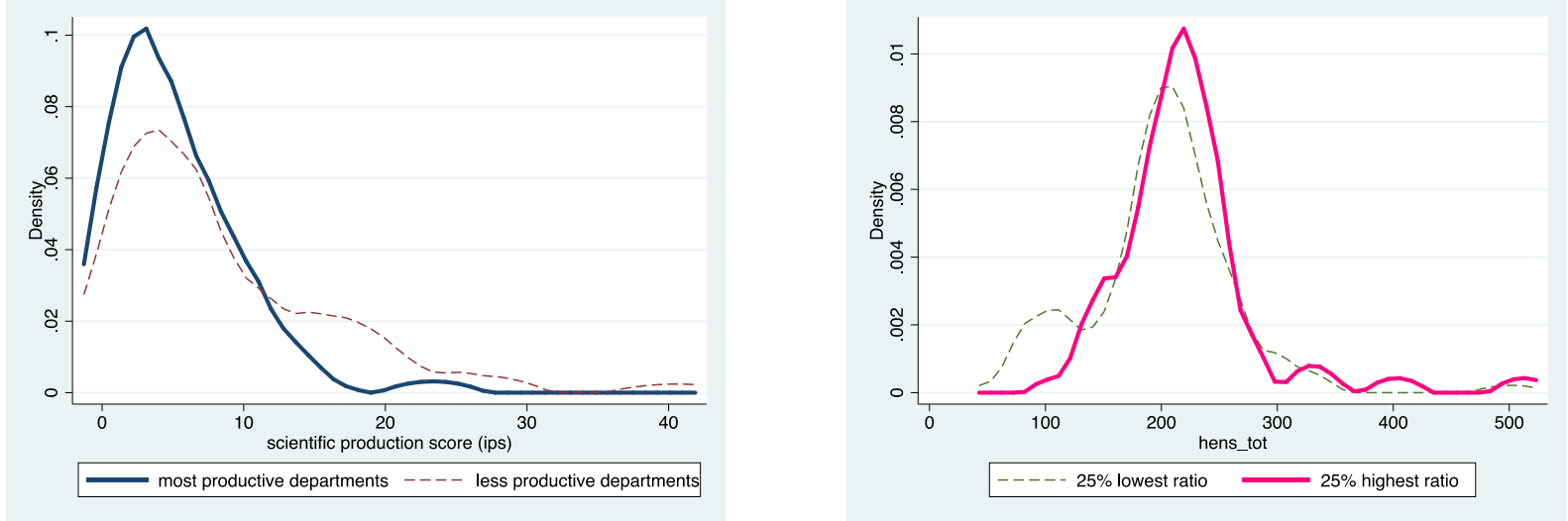

As Graph 4 clearly shows, the institutional context affects both individual scientific production and pedagogical investment. The median scientific score is about 8.22 when professors belong to the most productive departments, whereas it is only 5.05 for the least productive ones. Moreover, the average number of hours performed per year greater than 21 hours in understaffed teaching universities. These statistics argue for a more detailed study of the effect of context on multitasking. 


\section{Estimations and discussion}

To identify the effect of the scientific environment on professors' scientific production, we consider two substitutive tasks that face professors, such that investing in one tasks determines the time available to devote to the other task. In turn, we estimate the following the system of equations:

$$
\left\{\begin{array}{l}
\text { lips }_{i}=\alpha_{1} \text { lhens }_{i}+\beta_{1}{ }^{\prime} X_{i}+\delta_{1}{ }^{\prime} Z_{1 i}+\varepsilon_{1 i} \\
\text { lhens }_{i}=\alpha_{2} \text { lips }_{i}+\beta_{2}{ }^{\prime} X_{i}+\delta_{2}{ }^{\prime} Z_{2 i}+\varepsilon_{2 i}
\end{array}\right.
$$

where lips is the logarithm of scientific production index (ips), Ihens is the logarithm of teaching hours (hens), $X$ is a vector of individual attributes and $Z$ describes collective context in research and pedagogy.

To estimate this two-equation system, we solve a simultaneity problem that may cause a correlation in the error terms among the equations. We use a three-least squares estimation (Zellner and Theil, 1962), which adopts an instrumental variable approach to produce consistent estimates and generalized least squares (GLS) to account for the correlation structure in the disturbances across the two equations. We also control for heteroscedasticity with Greene's (2007) method. Moreover, we performed a Hansen-Sargan overidentification test (Davidson and MacKinnon, 2004; Baum et al., 2003), and we computed overall system R-square values (Greene, 2007). We estimate the two-equation system for the whole sample, and then separately for each type of professor (free-riders, research specialists, teaching specialists, generalists). Table 4 contains all the results.

Regarding the estimates' quality, the Hansen and Sargan overidentification test indicates that the models are well identified. The goodness of fit of our estimates is high (close to $80 \%$ ), though somewhat lower for the free-riders segment $\left(R^{2}=0.52\right)$. Explaining the behavior of these professors appears relatively difficult, probably due to the strong influence of unobserved heterogeneity. 
Table 4: Effects of the institutional context on professors' tasks ${ }^{\mathrm{ii}}$

\begin{tabular}{|c|c|c|c|c|c|c|c|c|c|c|}
\hline & \multicolumn{2}{|c|}{ Full sample } & \multicolumn{2}{|c|}{ Free-rider } & \multicolumn{2}{|c|}{ Specialist in research } & \multicolumn{2}{|c|}{ Specialist in teaching } & \multicolumn{2}{|c|}{ Generalist } \\
\hline & lips & Ihens & lips & Ihens & lips & Ihens & lips & Ihens & lips & Ihens \\
\hline Ihens & $\begin{array}{c}-2.295 \\
(0.579 * * *)\end{array}$ & & $\begin{array}{c}-14.103 \\
\left(30.921^{\text {ns }}\right)\end{array}$ & & $\begin{array}{c}-1.988 \\
\left(0.278^{* * *}\right)\end{array}$ & & $\begin{array}{c}-5.090 \\
(0.599 * * *)\end{array}$ & & $\begin{array}{c}-1.003 \\
(0.570 *)\end{array}$ & \\
\hline lips & & $\begin{array}{c}-0.245 \\
\left(0.015^{* * *}\right) \\
\end{array}$ & & $\begin{array}{c}-0.280 \\
(0.044 * * *) \\
\end{array}$ & & $\begin{array}{c}-0.416 \\
\left(0.045^{* * *}\right)\end{array}$ & & $\begin{array}{c}-0.012 \\
\left(0.019^{\text {ns }}\right)\end{array}$ & & $\begin{array}{c}0.141 \\
(0.019 * * *)\end{array}$ \\
\hline male & $\begin{array}{c}0.357 \\
\left(0.108^{* * *}\right)\end{array}$ & $\begin{array}{c}0.154 \\
\left(0.014^{* * *}\right) \\
\end{array}$ & $\begin{array}{c}1.957 \\
\left(4.389^{\mathrm{ns}}\right)\end{array}$ & $\begin{array}{c}0.112 \\
(0.026 * * *) \\
\end{array}$ & $\begin{array}{c}0.316 \\
\left(0.057^{* * *}\right)\end{array}$ & $\begin{array}{c}0.146 \\
\left(0.022^{* * *}\right)\end{array}$ & $\begin{array}{c}0.958 \\
(0.129 * * *) \\
\end{array}$ & $\begin{array}{c}0.151 \\
\left(0.016^{* * *}\right)\end{array}$ & $\begin{array}{c}-.021 \\
\left(0.062^{* * *}\right) \\
\end{array}$ & $\begin{array}{c}0.020 \\
\left(0.013^{\mathrm{ns}}\right)\end{array}$ \\
\hline exp: experience & $\begin{array}{c}-0.039 \\
\left(0.011^{* * *}\right) \\
\end{array}$ & $\begin{array}{c}-0.011 \\
\left(0.003^{* * *}\right) \\
\end{array}$ & $\begin{array}{c}-0.254 \\
\left(0.212^{\text {ns }}\right) \\
\end{array}$ & $\begin{array}{c}-0.025 \\
(0.007 * *) \\
\end{array}$ & $\begin{array}{c}-0.027 \\
\left(0.010^{* * *}\right) \\
\end{array}$ & $\begin{array}{c}-0.012 \\
\left(0.005^{* *}\right) \\
\end{array}$ & $\begin{array}{c}0.056 \\
\left(0.014^{* * *}\right) \\
\end{array}$ & $\begin{array}{c}0.010 \\
\left(0.003^{* * *}\right) \\
\end{array}$ & $\begin{array}{c}0.041 \\
\left(0.011^{* * *}\right) \\
\end{array}$ & $\begin{array}{c}-0.014 \\
\left(0.003^{* * *}\right) \\
\end{array}$ \\
\hline $\operatorname{exp2:} \exp ^{2}$ & $\begin{array}{c}0.0003 \\
\left(0.0002^{\text {ns }}\right) \\
\end{array}$ & $\begin{array}{c}0.0001 \\
\left(0.00006^{* *}\right) \\
\end{array}$ & $\begin{array}{c}0.004 \\
\left(0.002^{*}\right) \\
\end{array}$ & $\begin{array}{c}0.0004 \\
\left(0.0001^{* * *}\right) \\
\end{array}$ & $\begin{array}{c}0.0004 \\
\left(0.0002^{* *}\right) \\
\end{array}$ & $\begin{array}{c}0.0002 \\
\left(0.0001^{* *}\right) \\
\end{array}$ & $\begin{array}{c}-0.002 \\
\left(0.0003^{* * *}\right) \\
\end{array}$ & $\begin{array}{c}-0.0003 \\
\left(0.00006^{* * *}\right) \\
\end{array}$ & $\begin{array}{c}-0.001 \\
\left(0.0003^{* * *}\right) \\
\end{array}$ & $\begin{array}{c}0.0005 \\
\left(0.00006^{* * *}\right) \\
\end{array}$ \\
\hline jelC: mathematics & $\begin{array}{c}-0.073 \\
\left(0.082^{\text {ns }}\right)\end{array}$ & $\begin{array}{c}-0.037 \\
\left(0.020^{*}\right) \\
\end{array}$ & $\begin{array}{c}7.641 \\
\left(14.529^{\text {ns }}\right) \\
\end{array}$ & $\begin{array}{c}-0.026 \\
\left(0.093^{\mathrm{ns}}\right) \\
\end{array}$ & $\begin{array}{c}-0.488 \\
(0.109 * * *)\end{array}$ & $\begin{array}{c}-0.229 \\
(0.034 * * *)\end{array}$ & $\begin{array}{c}-1.335 \\
(0.109 * * *) \\
\end{array}$ & $\begin{array}{c}-0.099 \\
\left(0.021^{* * *}\right)\end{array}$ & $\begin{array}{c}-0.244 \\
(0.084 * * *)\end{array}$ & $\begin{array}{c}0.088 \\
\left(0.015^{* * *}\right) \\
\end{array}$ \\
\hline jelD: microeconomics & $\begin{array}{c}0.678 \\
(0.069 * * *) \\
\end{array}$ & $\begin{array}{c}0.178 \\
\left(0.021^{* * *}\right) \\
\end{array}$ & $\begin{array}{c}9.334 \\
\left(14.878^{\text {ns }}\right) \\
\end{array}$ & $\begin{array}{c}0.402 \\
\left(0.064^{* * *}\right) \\
\end{array}$ & $\begin{array}{c}-0.306 \\
\left(0.093^{* * *}\right) \\
\end{array}$ & $\begin{array}{c}-0.152 \\
(0.029 * * *) \\
\end{array}$ & $\begin{array}{c}-0.007 \\
\left(0.087^{\mathrm{ns}}\right) \\
\end{array}$ & $\begin{array}{c}-0.025 \\
\left(0.020^{\text {ns }}\right) \\
\end{array}$ & $\begin{array}{c}0.220 \\
\left(0.063^{* * *}\right) \\
\end{array}$ & $\begin{array}{c}0.042 \\
\left(0.015^{* * *}\right) \\
\end{array}$ \\
\hline jelE: macroeconomics & $\begin{array}{c}-0.043 \\
\left(0.080^{\text {ns }}\right)\end{array}$ & $\begin{array}{c}-0.052 \\
\left(0.015^{* * *}\right)\end{array}$ & $\begin{array}{c}0.820 \\
\left(1.118^{\text {ns }}\right)\end{array}$ & $\begin{array}{c}0.024 \\
\left(0.029^{\text {ns }}\right)\end{array}$ & $\begin{array}{c}-0.360 \\
\left(0.075^{* * *}\right)\end{array}$ & $\begin{array}{c}-0.174 \\
\left(0.028^{* * *}\right)\end{array}$ & $\begin{array}{c}-0.327 \\
\left(0.055^{* * *}\right)\end{array}$ & $\begin{array}{c}-0.024 \\
\left(0.015^{\mathrm{ns}}\right)\end{array}$ & $\begin{array}{c}0.052 \\
\left(0.051^{\text {ns }}\right) \\
\end{array}$ & $\begin{array}{c}-0.062 \\
\left(0.012^{* * *}\right)\end{array}$ \\
\hline jelHK: public economics & $\begin{array}{c}0.524 \\
\left(0.070^{* * *}\right) \\
\end{array}$ & $\begin{array}{c}0.141 \\
\left(0.020^{* *}\right)\end{array}$ & $\begin{array}{c}3.661 \\
\left(5.522^{\text {ns }}\right) \\
\end{array}$ & $\begin{array}{c}0.213 \\
\left(0.037^{\mathrm{ns}}\right) \\
\end{array}$ & $\begin{array}{c}0.769 \\
\left(0.076^{* * *}\right) \\
\end{array}$ & $\begin{array}{c}0.344 \\
\left(0.053^{* * *}\right) \\
\end{array}$ & $\begin{array}{c}0.043 \\
\left(0.074^{\text {ns }}\right) \\
\end{array}$ & $\begin{array}{c}-0.025 \\
\left(0.017^{\mathrm{ns}}\right) \\
\end{array}$ & $\begin{array}{c}0.346 \\
\left(0.075^{* * *}\right) \\
\end{array}$ & $\begin{array}{c}-0.175 \\
\left(0.018^{* * *}\right) \\
\end{array}$ \\
\hline hi0506: Lagged h-index & $\begin{array}{c}0.021 \\
\left(0.007^{* * *}\right) \\
\end{array}$ & & $\begin{array}{c}0.073 \\
\left(0.086^{\text {ns }}\right) \\
\end{array}$ & & $\begin{array}{c}0.002 \\
\left(0.005^{\mathrm{ns}}\right) \\
\end{array}$ & & $\begin{array}{c}0.037 \\
(0.003 * * *) \\
\end{array}$ & & $\begin{array}{c}0.063 \\
\left(0.006^{* * *}\right) \\
\end{array}$ & \\
\hline $\begin{array}{l}\text { citun: Department's } \\
\text { citation score }\end{array}$ & $\begin{array}{c}0.297 \\
\left(0.095^{* * *}\right)\end{array}$ & & $\begin{array}{c}0.313 \\
\left(2.103^{\mathrm{ns}}\right)\end{array}$ & & $\begin{array}{c}0.442 \\
\left(0.138^{* * *}\right)\end{array}$ & & $\begin{array}{c}1.003 \\
(0.103 * * *)\end{array}$ & & $\begin{array}{c}0.541 \\
(0.174 * * *)\end{array}$ & \\
\hline citun2: $(\text { citun })^{2}$ & $\begin{array}{c}-0.045 \\
\left(0.014^{* * *}\right)\end{array}$ & & $\begin{array}{c}-0.695 \\
\left(1.286^{\mathrm{ns}}\right)\end{array}$ & & $\begin{array}{c}-0.073 \\
\left(0.023^{* * *}\right)\end{array}$ & & $\begin{array}{c}-0.258 \\
(0.023 * * *)\end{array}$ & & $\begin{array}{c}-0.119 \\
\left(0.037^{* * *}\right)\end{array}$ & \\
\hline $\begin{array}{l}\text { scorup: great increase in } \\
\text { collective impact factor }\end{array}$ & $\begin{array}{c}-0.071 \\
\left(0.026^{* * *}\right)\end{array}$ & & $\begin{array}{c}1.168 \\
\left(2.654^{\text {ns }}\right) \\
\end{array}$ & & $\begin{array}{c}-0.070 \\
(0.037 * * *)\end{array}$ & & $\begin{array}{c}-0.347 \\
(0.091 * * *)\end{array}$ & & $\begin{array}{c}-0.226 \\
\left(0.055^{* * *}\right) \\
\end{array}$ & \\
\hline $\begin{array}{l}\text { ratio: Student per } \\
\text { professor }\end{array}$ & & $\begin{array}{c}0.048 \\
(0.018 * * *) \\
\end{array}$ & & $\begin{array}{c}-0.028 \\
\left(0.037^{n s}\right) \\
\end{array}$ & & $\begin{array}{c}0.024 \\
\left(0.053^{\text {ns }}\right) \\
\end{array}$ & & $\begin{array}{c}0.143 \\
(0.074 *) \\
\end{array}$ & $\begin{array}{c}6.683 \\
\left(3.262^{* *}\right)\end{array}$ & $\begin{array}{c}0.091 \\
\left(0.018^{* * *}\right) \\
\end{array}$ \\
\hline ratio2: ratio $^{2}$ & & $\begin{array}{c}-0.001 \\
\left(0.0004^{* *}\right)\end{array}$ & & $\begin{array}{c}0.001 \\
\left(0.001^{\mathrm{ns}}\right)\end{array}$ & & $\begin{array}{l}-0.0005 \\
\left(0.001^{\text {ns }}\right) \\
\end{array}$ & & $\begin{array}{c}-0.003 \\
\left(0.002^{*}\right)\end{array}$ & & $\begin{array}{c}-0.002 \\
\left(0.0004^{* * *}\right) \\
\end{array}$ \\
\hline constant & $\begin{array}{c}13.330 \\
\left(3.154^{* * *}\right) \\
\end{array}$ & $\begin{array}{c}5.127 \\
(0.219 * * *) \\
\end{array}$ & $\begin{array}{c}76.974 \\
\left(160.532^{\mathrm{ns}}\right) \\
\end{array}$ & $\begin{array}{c}5.589 \\
(0.389 * * *) \\
\end{array}$ & $\begin{array}{c}11.944 \\
(1.397 * * *)\end{array}$ & $\begin{array}{c}5.811 \\
(0.632 * * *) \\
\end{array}$ & $\begin{array}{c}27.143 \\
(3.144 * * *) \\
\end{array}$ & $\begin{array}{c}3.906 \\
(0.730 * * *) \\
\end{array}$ & $\begin{array}{c}6.683 \\
\left(3.262^{* *}\right) \\
\end{array}$ & $\begin{array}{c}4.426 \\
\left(0.183^{* * *}\right) \\
\end{array}$ \\
\hline $\begin{array}{l}\text { Observations } \\
\mathrm{R}^{2} \\
\text { Hansen-Sargan test value }\end{array}$ & \multicolumn{2}{|c|}{$\begin{array}{c}240 \\
0.891\end{array}$} & \multicolumn{2}{|c|}{$\begin{array}{c}57 \\
0.524\end{array}$} & \multicolumn{2}{|c|}{$\begin{array}{c}63 \\
0.792\end{array}$} & \multicolumn{2}{|c|}{$\begin{array}{l}61 \\
798\end{array}$} & 19 & \\
\hline
\end{tabular}


According to results in table 4, the tasks are conflicting, as predicted in our model. When we consider the tasks simultaneously, we find that investing heavily in one activity limits the time available for other, except for among free riders. Moreover, we observe that for both generalists and specialists, the between-task elasticities are asymmetric: The negative influence of teaching activities on scientific production is always stronger than the negative effect of publishing on pedagogical duties. This result likely is a direct consequence of the statutory teaching hours (192 hours) and the asymmetric flexibility around this threshold value. Increasing teaching hours above this level is easy for each professor in the French academia, but it is less easy to perform less. Only professors who invest in administrative activities or defend a sabbatical can negotiate a reduction in their teaching duties. Moreover, when a professor receives an agreement to teach less during a given next academic year, his or her courses get affected to other professors, and there is no guarantee for the incumbent to recover these courses in the future. Not surprisingly, it is thus easier to adjust research activities when teaching tasks increase. Conversely, it seems to be harder to reduce teaching duties when a professor wants to invest more in research activities, demonstrating the existence of a ratcheting effect.

Although research and pedagogical activities are substitutable for professors, they are complementary for universities (principals), which have an interest in seeing teachers do both tasks simultaneously. This divergence of interests between the principal and agents requires a better understanding of the determinants of investments in both tasks to design relevant incentive schemes. Our estimates identify precisely which variables explain such investments.

They depend primarily on individual characteristics. Men invest more time, on average, in both tasks than women. Following Becker (1957), female professors could face more challenges in combining their professional activity with family responsibilities. However, the gender effect also differs according to professors' types. For generalists for example, men show presents lower scientific production scores and equivalent teaching and administrative duties, perhaps as a result of gender differences in multitasking abilities (Criss, 2006). In this case, women might be more productive than men in multitasking activities, whereas men are globally more efficient because they specialize.

Our results also confirm a negative impact of experience on both publication scores and pedagogical duties. A life cycle thus seems likely, in that experience consistently produces a negative effect that worsens over time in our data. This finding may appear surprising, but we note that our sample consists of only full professors, who all have substantial experience. We probably even miss the period of massive investment in scientific production that professors undergo to maximize their chances of promotion and tenure or for greater remuneration in the early stages of their careers.

We also find a path dependency effect among the publication scores: Professors with high past $h$ indexes are more productive, in accordance with a Matthew effect for French economics professors. This effect could indicate that the most productive professors have easier access to funds, attract the best coauthors, and are recruited by the best laboratories. Because of their better research environments, they enjoy an advantage in scientific production. The Matthew effect also could mean that the most productive professors have specific research skills, which arise throughout their careers. 
Our results also extend findings by Rauber and Ursprung (2008), who concluded that research fields significantly affect scientific output. These fields also have an impact on the number of teaching hours, according to our findings. For example, specialists in public economics have a comparative advantage in the production of science and are frequently solicited to teach. This advantage could be attributed to the central role of this field in current economics research, as well as in economic policy (e.g., pollution issues, imperfect competition, social equity).

Our results confirm the key prediction of our model: A dynamic scientific context (citun) favors individual scientific production by all professors, except for free riders. This finding also is consistent with the conclusions of economics of science theory; not only do we include the collective dimension of research, but we also account for multitasking. The positive effects of a dynamic research environment are stronger for teaching specialists and for generalists. The creation of agglomeration effects, as recommended by Aghion (2010), therefore can increase the scientific output of all professors, including those who initially do not have the strongest research abilities. Moreover, our results allow us to make two points about the impact of agglomeration effects. First, the positive effects of a dynamic research environment seem to diminish gradually as the universities' impact factors rise (citun2), as we expected. Agglomeration effects thus are characterized by diminishing returns. Second, a gradual implementation of these agglomeration effects appears preferable; belonging to a university that experiences a sharp increase (relative to the median) of its impact factor (scorup) actually is unfavorable for individual scientific output. This result may emerge because the sudden improvement of an impact factor generally follows sweeping university governance reforms, such as mergers of research teams. These changes can create tensions and, at least in the short term, adversely affect scientific output.

Moreover, teaching activities depend also on the context. Working in an understaffed university (higher ratio of students per professor) significantly increases the number of teaching hours undertaken by a professor. This pedagogical context affects both generalists and teaching specialists; it does not change behaviors of research specialists or free riders.

\section{Conclusion}

We have analyzed the determinants of scientific production, including collective determinants related to the research environment, in the context of multitasking teachers. In this sense, we combine the key features of the economics of science with the personnel economics.

We propose a principal-agent model to understand how university professors divide their time between two substitutable tasks: publishing and teaching. Our theoretical framework predicts that professors devote more time to the task for which they have a marginal advantage. According to their abilities, they can be either generalists or specialists. However, the scientific context, and especially collective scientific production, strongly influences these optimal behaviors too. Thus, a dynamic context characterized by a high stock of knowledge in the research lab or university improves individual publication scores by creating positive knowledge externalities. 
To test these predictions, we used French data from administrative sources. This original data set enables us to observe both scientific production and pedagogical duties. Our results also confirm that these tasks are conflicting and that the institutional context affects the activity choices that professors make.

Finally, we conclude that universities, or the principals in our principal-agent framework, can influence the activities of their agents (professors) by implementing appropriate incentive schemes, such as assigning professors to the tasks for which they are inherently more talented. They also can play on collective research aspects by favoring dynamic scientific contexts (including agglomeration effects) that increase scientific output in total. 


\section{References}

Adams J., Griliches Z., 1996, "Measuring Science: An Exploration", Proceedings of the National Academy of Science, vol.93, pp.12664-12670.

Aghion P., 2010, L'Excellence Universitaire : Leçons des Expériences Internationales, Rapport remis à la Ministre de l'Enseignement et de la Recherche

Allison P.D., Long J.S., 1990, "Departmental Effects on Scientific Productivity", American Sociological Review, $\mathrm{n}^{\circ} 55, \mathrm{pp} .469-478$.

Baum C.F., Schaffer M.E., Stillman S., 2003, "Instrumental Variables and GMM: Estimation and Testing", Stata Journal, vol.3, pp.1-31.

Becker G., 1957, The Economics of Discrimination, Chicago University Press, Chicago, Reprint 1971.

Bonaccorsi A., Daraio C., 2003, "Age Effects in Scientific Productivity. The Case of the Italian National Research Council (CNR)", Scientometrics, vol. 58, n¹, pp.47-88.

Bosquet C., Combes P.P., 2011, “Un Panorama de la Recherche Française en Economie Comparant les Approches Google Scholar et Econlit", GREQAM Working Paper.

Carayol N., Matt M., 2004, "Does Research Organization Influence Academic Production? Laboratory Level Evidence from a Large European University", Research Policy, vol.33, n8, pp.1081-1102.

Carayol N., Matt M., 2006, "Individual and Collective Determinants of Academic Scientists' Productivity", Information Economics and Policy, vol.18, $\mathrm{n}^{\circ} 1$, pp.55-72.

Cole S., Cole J., 1973, Social Stratification in Science, University of Chicago Press, Chicago.

Criss B.R., 2006, "Gender Differences in Multitasking", Working Paper, Department of Psychology, Missouri Western State University.

Dasgupta P., David P.A., 1994, "Toward a New Economics of Science”, Research Policy, n²3, pp.487-521.

Davidson R., MacKinnon J., 2004, Econometric Theory and Methods, New York: Oxford University Press.

Diamond A.M., 1986, "The Life-Cycle Research Productivity of Mathematicians and Scientists", The Journal of Gerontology, n41, pp.520-525.

Fox M.F., 1992, "Research, Teaching and Publication Productivity: Mutuality versus Competition in Academia", Sociology of Education, vol.65, pp.293-305.

Harzing A. W., 2010, The Publish or Perish Book, Tarma Software Research Pty Ltd, Melbourne Australia, 266 pages.

Hirsch J. E., 2005, "An Index to Quantify an Individual's Scientific Output", Proceedings of the National Academy of Science, vol.102, n46, pp. 16569-16572.

Holmstrom B., Milgrom P., 1991, "Multitask Principal-Agent Analyses: Incentive Contracts, Asset Ownership, and Job Design", Journal of Law, Economics and Organization, vol.7, pp.24-52.

Lazear E.D., 1995, Personnel Economics, MIT Press.

Levy Garboua L., 2008, “Rapport sur le Premier Concours National d’Agrégation de l'Enseignement Supérieur pour le Recrutement des Professeurs des Universités en Sciences Economiques (année 2007-2008) ", Revue d'Economie Politique, vol.118, n5, pp.603-623.

Lissoni F., Mairesse J., Montobbio F., Pezzoni M., 2011, "Scientific Productivity and Academic Promotion: A Study on French and Italian Physicists", Industrial and Corporate Change, Oxford University Press, vol. 20(1), pp.253-294.

Long J.S., McGinnis R., 1981, "Organizational Context and Scientific Productivity", American Sociological Review, $\mathrm{n}^{\circ} 46, \mathrm{pp} .422-442$.

Lotka A.J., 1926, "The Frequency Distribution of Scientific Productivity", Journal of the Washington Academy of Sciences, vol.16, $n^{\circ} 512$, pp.317-323.

Merton R.K., 1968, "The Matthew Effect in Science", Science, vol.159, n³810, pp.56-63.

MacDonald G., Marx L.M., 2001, “Adverse Specialization”, Journal of Political Economy, vol.109, n¹, pp. 864899.

Mairesse J., Turner L., 2002. "A Look at Individual Differences in Scientific Research Productivity: An Econometric Analysis of the Publications of the French CNRS Physicists in Condensed Matter (19801997)", Conference "Rethinking Science Policy: Analytical Frameworks for Evidence-Based Policy", SPRU, Brighton, March 21-23.

Prasad S., 2009, "Task Assignments and Incentives: Generalists versus Specialists", Rand Journal of Economics, vol.40, n², pp.380-403.

Rauber M., Ursprung H. W.,2008, "Life Cycle and Cohort Productivity in Economic Research: the Case of Germany", German Economic Review, pp.431-456.

Rosen S., 1982, “Authority, Control, and the Distribution of Earnings", Bell Journal of Economics, n¹3, pp.311-323. 
Sattinger M., 1975, "Comparative Advantage and the Distributions of Earnings and Abilities", Econometrica, Vol.43, pp.455-468.

Schneider A., 1998, "Why Don't Women Publish as Much as men? ", Chronicle of Higher Education, vol.45, pp.14-16.

Stephan P.E., 1996, "The Economics of Science”, Journal of Economic Literature, vol.34, pp.1199-1235.

Stephan P.E., Levin S.G., 1997, "The Critical Importance of Careers in Collaborative Scientific Research", Revue $d^{\prime}$ Economie Industrielle, $\mathrm{n}^{\circ} 79$, pp.45-61.

Stephan P.E., 1998, "Gender Differences in the Rewards to Publishing in Academe: Science in the 70's", SEX Roles, vol. 38, pp.11-12.

Thiele V., 2010, "Task-specific Abilities in Multi-Task Principal Agent Relationships", Labour Economics, vol.17, pp.690-698.

Waldman M., 1984, "Worker Allocation, Hierarchies and the Wage Distribution", Review of Economics Studies, vol.51, pp.95-109.

Zellner A., Theil H., 1962, "Three Stage Least squares: Simultaneous Estimate of Simultaneous Equations", Econometrica, vol.29, pp.54-78.

\section{Appendix}

Suppose that $x$ defines the wage that an agent receives. Payments are equal for all outcomes, so the individual rationality constraint becomes $u\left(w_{i}\right) \geq u_{0}+\alpha t_{i}+\beta\left(1-t_{i}\right)$.

This constraint must be binding, so $x_{i} \geq u^{-1}\left(u_{0}+\alpha t_{i}+\beta\left(1-t_{i}\right)\right)$

If we define $h=u^{-1}$, the principal must solve the following problem:

The first order condition of this problem is:

$$
\operatorname{Max}_{i} 4 \bar{y}+2 a \sqrt{t_{i}}+2 b \sqrt{1-t_{i}}-h\left(u_{0}+\alpha t_{i}+\beta\left(1-t_{i}\right)\right)
$$

$$
\frac{a}{\sqrt{t_{i}}}-\frac{b}{\sqrt{1-t_{i}}}-(\alpha-\beta) \times h^{\prime}\left(\alpha t_{i}+\beta\left(1-t_{i}\right)+u_{0}\right)=0
$$

The resolution is equivalent when we introduce scientific externalities. In this case, the principal's problem is given by:

and the first-order condition becomes:

$$
\operatorname{Max}_{i} 2 a t_{i} \sqrt{N}+2 b \sqrt{1-t}+4 \bar{y}-h\left(u_{0}+\alpha t_{i}+\beta\left(1-t_{i}\right)\right)
$$

$$
2 a \sqrt{N}-\frac{b}{\sqrt{1-t_{i}}}=(\alpha-\beta) \times h^{\prime}\left(\alpha t_{i}+\beta\left(1-t_{i}\right)+u_{0}\right)
$$

\footnotetext{
${ }^{\mathrm{i}}$ For example, a President of an University receives a premium equivalent to 192 teaching hours.

ii Standard deviations are given in brackets.

NB: ${ }^{* *}$ : significant at $1 \%$; ${ }^{* *}$ : significant at $5 \%$; significant at $10 \%$; ns: non significant
} 